\title{
Hubungan antara Perceived Organizational Support dengan Organizational Commitment pada Anggota Organisasi UKKI
}

\author{
Ikhwan Fadlu Fantazilu*1, Magdalena Ayu Agustin², I Gusti Ayu Agung Istri Risna Prajna Devi ${ }^{3}$ \\ 1,2,3 Universitas Negeri Surabaya \\ Jl. Lidah Wetan, Kecamatan Lakarsantri, Kota Surabaya, Jawa Timur \\ *ikhwan.18142@mhs.unesa.ac.id
}

\begin{abstract}
Abstrak-This study aims to find out the relationship between perceived organizational support and organizational commitment to UKKI members. This research design was quantitative with 70 UKKI members recruited through accidental sampling technique. The data was obtained then tested first into the classical assumption test, which consists test of normality and homogeneity. Then, after the data passed the classical assumption test, the data was continued with the pearson correlation test. The results showed that there was a significant correlation between perceived organizational support and organizational commitment and the $p$ value $=0,001<0,05$. The implication of this research shows that in order to increase the commitment of UKKI members, UKKI must be able to provide beneficial support for its members during Covid 19 pandemic period such as by maintaining intense communication and many more.

Keywords : Covid 19 Pandemic; Organizational Commitment; Perceived Organizational Support; UKKI.
\end{abstract}

\begin{abstract}
Abstrak
Penelitian ini memiliki tujuan untuk mencari tahu hubungan antara perceived organizational support terhadap organizational commitment pada anggota UKKI. Adapun desain penelitian ini ialah kuantitatif dengan jumlah subjek sebanyak 70 orang anggota UKKI yang direkrut melalui teknik accidental sampling. Data yang diperoleh kemudian diuji terlebih dahulu ke dalam uji asumsi klasik yang terdiri atas uji normalitas dan homogenitas. Kemudian setelah data dinyatakan lolos uji asumsi klasik, data akan diolah pada uji korelasi pearson. Hasil penelitian inimenunjukkan terdapat korelasi signifikan antara perceived organizational support dengan organizational commitment dengan nilai korelasi $p=0,001<0,05$. Implikasi dari penelitian menunjukkan bahwa untuk meningkatkan komitmen anggota UKKI, maka organisasi UKKI harus bisa menyediakan dukungan yang baik bagi anggotanya selama masa pandemi seperti dengan cara menjaga komunikasi yang intens dan lain sebagainya.
\end{abstract}

Kata Kunci -Pandemi Covid 19; Komitmen Organisasi; Persepsi Dukungan Organisasi; UKKI.

\section{PENDAHULUAN}

Pandemi Covid 19 memberikan efek multisektor, tidak terkecuali pengaruhnya bagi nasib di organisasi. Setelah dinyatakan pertama kali adanya kasus Covid 19 di Indonesia, pemerintah sendiri melalui Peraturan Pemerintah Republik Indonesia No. 21 Tahun 2020 menyatakan bahwa pencegahan penyebaran transimisi Covid 19 tetap harus menjadi prioritas [1]. Akibatnya, berbagai pembatasan gerakan dan adaptasi kebiasaan baru seperti memakai masker, rajin mencuci tangan, dan menjaga jarak. Selain itu, berbagai kebijakan lain juga turut digalakkan seperti halnya Pembatasan Sosial Berskala Besar (PSBB) yang diikuti dengan kebijakan merumahkan aktivitas lain seperti belajar dan bekerja [2]. Organisasi seperti halnya perkantoran, lembaga pendidikan, pabrik, komunitas pemuda, dan lain-lain dianjurkan untuk dapat sebisa mungkin meminimalisir hubungan secara luring (langsung) dan melakukan subtitusi dengan via hubungan daring (online), seperti melalui sambungan Zoom, Google Meet dan berbagai aplikasi lainya.

Tabel 1. Data Anggota UKKI

\begin{tabular}{llll}
\hline No. & $\begin{array}{l}\text { Tahun } \\
\text { Angkatan }\end{array}$ & Jumlah Pelamar & $\begin{array}{l}\text { Jumlah } \\
\text { Anggota } \\
\text { Aktif }\end{array}$ \\
\hline 1. & 2018 & 154 & 16 \\
\hline 2. & 2019 & 130 & 32 \\
\hline 3. & 2020 & 114 & 48
\end{tabular}

Secara umum, sebagian besar aktifitas yang harus dilaksanakan via daring cenderung memiliki dampak pada penurunan komitmen organisasi [3]. Begitupun halnya pada organisasi global [4]. Padahal ada atau tidaknya komitmen dalam anggota sebuah organisasi dapat mempengaruhi produktifitas keinerja maupun kemajuan suatu organisasi [5].

Salah satu bukti nyata adanya dampak pandemi terhadap organisasi juga tercermin dari kasus yang dialami organisasi kemahasiswaan UKKI Universitas 
Negeri Surabaya. UKKI itu sendiri ialah kependekan dari Unit Kegiatan Kemahasiswaan Islam yakni suatu organisasi yang berfokus di dalam upaya dakwah dan kaderisasi ajaran islam di region Universitas Negeri Surabaya. Lebih lanjut, UKKI adalah organisasi yang berdiri sejak tahun 1988 di saat Unesa masih bernama IKIP Surabaya. Selain berdakwah, fungsi dari adanya organisasi ini ialah guna kaderisasi dan pengembangan skill mahasiswa melalui kegiatan-kegiatan bernuansa islami. Adapun beberapa contoh dari kegiatan UKKI tersebut adalah BKM (Bukti Karya Mahasiswa) yang merupakan agenda tahunan berupa pengabdian kepada masyarakat selama kurang lebih 10 hari membangun desa tertinggal baik dari segi pendidikan, bahkan segi ekonomi. Selain itu, terdapat juga program pesantren kampus yaitu program selama dua hari pada bulan ramadhan yang berisikan kegiatan sahur bersama, qiyamul laili, tadarus, diikuti giat buka bersama, dan ceramah milenial. Selanjutnya, UKKI juga memiliki program yang bernama studi islam intensif yaitu melakukan diskusi problematik umat untuk kemudian merumuskan solusi berdasarkan perspektif islam, serta berbagai kegiatan lainnya. Namun sayangnya, dengan bergulirnya masa pandemi ini, banyak kegiatan dari organisasi UKKI yang mengalami perubahan bahkan penghentian. Beberapa di antaranya bertujuan untuk mengurangi resiko penyebaran Covid 19 dan sebagian lainya dialihkan secara daring menggunakan Zoom. Meski demikian, data laporan organisasi menunjukkan bahwa jumlah anggota UKKI mengalami penurunan selama pandemi. Hal ini dapat dilihat pada tabel 1.0 di mana keikutsertaan mahasiswa ke dalam kegiatan di UKKI turun dan bahkan dari tahun ke tahun jumlah anggota tersebut juga mengalami penurunan anggota pelamar. Dengan demikian, adanya fenomena tersebut mengindikasikan lemahnya komitmen organisasi pada para anggota UKKI.

\section{KAJIAN PUSTAKA \\ A. KOMITMEN ORGANISASI}

Komitmen organisasi atau organizational commitment merupakan suatu kondisi keterikatan yang dialami oleh anggota organisasi terhadap organisasi tempat dirinya bernaung [6]. Meski demikian, tidak sedikit para pakar yang mendefinisikan komitmen organisasi secara berbeda-beda. Seperti, Steers [7] menyebut komitmen organisasi sebagai "The relative strength of individual in identifying their involvement in the organization", atau menekankan komitmen sebagai wujud dari keterlibatan. Sedangkan menurut Hrebiniak dan Alluto [8] "Organizational commitment is the unwillingness to leave the organization for increments in pay, status, or proffesional freedom, or for greater collegueal friendship", atau dengan kata lain komitmen organisasi merupakan ketidakinginan seseorang meninggalkan organisasi karena berbagai pertimbangan. Selain itu, komitmen organisasi juga disebut sebagai penerimaan terhadap tujuan dan minat organisasi, "The totallity of internalized normative pressures to act in a way which meets organizational goals and interests" [9]. Di sisi lain, komitmen organisasi juga mencakup seberapa jauh seorang anggotamengidentifikasi dirinya selayaknya keinginan organisasi, "The strength of individuals identification with an organization" [10]. Dari berbagai definisi tersebut maka telah dapat dianalisa bahwa komitmen organisasi meliputi keterikatan, penerimaan terhadap tujuan dan nilai, serta mengidentifikasi tujuan dan nilai organisasi tersebut sebagai tujuan dan nilai personal [11].

Meyer \& Allen [6] telah membagi komitmen organisasi ke dalam tiga komponen, antara lain yaitu: (1) affective commitment, (2) normative commitment, (3) continuance commitment. Pertama, yaitu affective commitment merujuk pada perasaan atau emosional yang merasa gembira ketika ia menjadi bagian atas organisasi. Lalu kedua, normative commitment yaitu keterikatan seseorang dalam organisasi karena adanya kesadaran untuk berkewajiban akan tugas di dalamnya atau dengan kata lain individu enggan meninggalkan organisasi karena merasa bertanggung jawab atas segala hal di dalam organisasinya. Ketiga, continuance commitment atau ketidakinginan untuk meninggalkan organisasi akibat berbagai pertimbangan seperti peran kompensasi, hubungan pertemanan, dan lain-lain.

Lebih lanjut, indikasi orang-orang yang memiliki komitmen organisasi biasanya dapat dicirikan dengan perasaan senang ketika harus berlama-lama tinggal di dalam organisasi, merasa ingin selalu terlibat, dan merasa yakin serta menerapkan nilai-nilai yang dianut oleh organisasinya tersebut. Selain itu, seseorang yang berkomitmen juga dicirikan dengan merasa khawatir meninggalkan organisasi karena adanya pertimbangan resiko kerugian yang akan hilang dari dirinya ketika ia pergi. Kemudian ketika memiliki komitmen, seseorang biasanya merasa bangga, bahkan ia pun rela berkorban demi organisasinya, dan bertanggung jawab terhadap tugas yang diberikan padanya [12]. Sebagai tambahan, orang yang berkomitmen tinggi terhadap organisasi juga memiliki insiatif untuk berbagi atas apa yang ia bisa lakukan dan miliki pada anggota lain di dalam organisasi dengan tujuan agar dapat mempermudah jalanya organisasi mencapai tujuan, ataudengan kata 
lain ia merasa bahwa orang lain di dalam organisasinya tersebut adalah bagian dari keluarga [13].

Adanya anggota organisasi yang berkomitmen memiliki berbagai implikasi positif dalam memajukan organisasi, di antaranya adalah dapat meningkatkan produktifitas organisasi. Hal ini bisa dicapai apabila setiap anggota mampu menujukan etos kerja yang baik, jarang absen, dan tidak sering terjadi pergantian atau turnover anggota. Adapun sebaliknya, organisasi akan mengalami kerugian jika banyak di antara anggota di dalamnya tidak memiliki komitmen, seperti rentan keluar sehingga harus melakukan recruitment dan seleksi ulang, lalu perihal tidak komitmen juga dapat memicu suasana tegang bahkan konflik [9]. Oleh karena itu topik-topik terkait komitmen organisasi merupakan topik penting yang harus diselesaikan. Di sisi lain, literatur telah menyebutkan bahwa komitmen organisasi dapat dipengaruhi oleh banyak variabel, seperti: organizational citizenship behavior [19], job security [14], organizational culture [12], job satisfaction [15], perceived organizational support [16], dan lain sebagainya. Adapun di dalam penelitian ini, peneliti hanya menguji peran POS (perceived organizational support) sebab UKKI memiliki masalah dengan proses adaptasi pola berorganisasi dari konvensional menjadi digital, sehingga sangat memungkinkan rekonstruksi pola kerja tersebut diduga telah berdampak pada POS dan berujung pada rendahnya komitmen organisasi.

\section{B. PERSEPSI DUKUNGAN ORGANISASI}

POS atau perceived organizational support ialah persepsi yang dimiliki oleh anggota organisasi dalam menilai secara menyeluruh apakah organisasi yang ditempatinya telah dapat memberikan dukungan serta kesejahteraan bagi para anggotanya [16]. Selain itu, Rhoades dan Eisenberger [17] menyebutkan bahwa perceived organizational support ialah penilaian oleh anggota organisasi yang meliputi seberapa besar nilai kontribusi, dukungan, kepedulian organisasi terhadap kesejahteraan para anggotanya. Dengan demikian inti dari variabel POS adalah persepsi anggota terhadap kemampuan organisasi memberikan dukungan hingga ia dapat merasakan sejahtera. Lebih lanjut, dimensi perceived organizational support terdiri atas dua hal. Pertama, penghargaan terhadap berbagai kontribusi yang dilakukan oleh anggotanya seperti dengan cara memperhatikan hadiah, lalu menyediakan pengakuan, promosi, dan akses ke informasi yang mudah atau lain sebagainya, dengan tujuan untuk mempermudah job description yang diemban anggotanya. Kedua, yaitu memperdulikan kesejahteraan anggota melalui cara mendengarkan opini serta keluhan karyawan dengan bijaksana [17].

Dikutip dalam Robbins \& Judge [18], persepsi dukungan organisasi dengan sengaja mencari tahu persepsi anggota secara subjektif dengan tujuan guna menggambarkan pendapat individu satu dengan yang lain untuk menilai kondisi kesejahteraan yang telah diupayakan oleh organisasi. Dari pendapat satu per satu anggota tersebut kemudian akan terkumpul persepsi kolektif terkait apa yang sudah diberikan organisasi sehingga akan dirasa objektif dalam mengambarkan fenomena mendekati fakta. Selain itu, pengukuran individual pada konstruk POS juga dirasa lebih sesuai terutama untuk mencari tahu persoalan terkait aspekaspek subjektif lainya yang melatarbelakangi suatu masalah dalam organisasi. Lebih lanjut, orang yang memiliki nilai perceived organizational support yang tinggi akan memunculkan sikap-sikap positif diikuti perilaku kerja yang sesuai dengan apa yang diinginkan oleh organisasi [19].

Dengan demikian, adanya fenomena turnover atau keluar masuk anggota yang mengindikasikan kurangnya komitmen pada organisasi UKKI, maka penelitian ini bertujuan untuk mengetahui hubungan antara persepsi dukungan organisasi dengan komitmen organisasi pada anggota UKKI selama pandemi Covid 19. Adapun hipotesis yang diajukan adalah "Terdapat Hubungan antara Perceived Organizational Support dengan Organizational Commitment pada Anggota UKKI atau Unit Kegiatan Kerohanian Islam Unesa selama Pandemi Covid 19".

\section{METODE PENELITIAN}

Berdasarkan jenis penelitianya, penelitian ini tergolong sebagai basic research atau dengan kata lain penelitian ini memiliki tujuan untuk mendeskripsikan, memahami, dan memprediksi suatu fenomena untuk dapat mendasari terbentuknya intervensi [20]. Adapun dalam konteks penelitian ini, peneliti berusaha untuk mendeskripsikan hubungan perceived organizational support dengan organizational commitment pada anggota UKKI selama pandemi Covid 19.

Data dalam penelitian ini dikumpulkan melalui kuesioner, yaitu suatu teknik pengumpulan data yang dilakukan dengan cara menyebarkan daftar pernyataan kepada responden, di mana para responden itu akan memberikan respon berdasar self-report [21]. Lebih lanjut, kuesioner juga akan dibagi menjadi dua, yaitu kuesioner organizational commitment yang disusun atas pendapat Meyer \& Allen yang kemudian telah diadaptasi ke dalam bahasa Indonesia oleh Afni \& Saragih [12]. Lalu, kuesioner perceived organizational 
support oleh Eisenberger namun telah diadaptasi oleh Mujiasih [16]. Adapun skala kuesioner menggunakan skala likert yang terdiri atas lima poin, yaitu merentang dari angka satu untuk mengindikasikan pilihan sangat setuju hingga angka lima yang berarti sangat tidak setuju. Jumlah keseluruhan item kuesioner yakni 18 item, dengan 10 item yang menguji organizational commitment sedangkan 8 yang lain menguji perceived organizational support (POS). Selanjutnya, kuesioner disajikan melalui bantuan google form dan disebarkan kepada sampel berjumlah 70 anggota aktif UKKI yang diambil menggunakan teknik pengambilan sampel yaitu accidental sampling [22].

Setelah data terkumpul, proses berikutnya adalah melakukan analisis data untuk menginterpretasikan atau mencari jawaban hipotesis yang diajukan. Dalam penelitian ini peneliti menggunakan Uji Korelasi Product Moment dan sebelum masuk ke dalam langkah analisis korelasi tersebut, terlebih dahulu data akan diuji ke dalam Uji Asumsi Klasik yang terdiri atas Uji Normalitas dan Uji Homogenitas. Setelah dinyatakan lolos Uji Asumsi Klasik, maka data dapat dilanjutkan ke tahapan Uji Korelasi tersebut. Untuk mempermudah penyajian data, di sini peneliti menggunakan bantuan software JASP (Jeffrey's Amazing Statistics Program) untuk melakukan analisa-analisa terkait di atas.

\section{HASIL DAN PEMBAHASAN}

Hasil analisa JASP di mulai dari Uji Validitas dan Uji Reliabilitas alat ukur, kemudian diikuti dengan Uji Asumsi Klasik yang terdiri atas Uji Normalitas serta Uji Homogenitas. Terakhir yaitu interpretasi hipotesis menggunakan Uji Korelasi Product Moment Pearson.

Tabel 2. Hasil Uji Validitas Instrumen

\section{Chi-Square Test}

\begin{tabular}{lccc}
\hline Model & $\mathbf{X}^{\mathbf{2}}$ & df & $\mathbf{p}$ \\
\hline Baseline model & 650.671 & 153 & \\
\hline Factor model & 234.269 & 134 & $<.001$ \\
\hline
\end{tabular}

Pertama, yaitu uji validitas alat ukur atau dengan kata lain menguji apakah alat ukur yang digunakan telah sesuai dengan apa yang ditujukan. Pada tabel 2.0 terlihat bahwa skor $p<0.001$ yang artinya ialah alat ukur telah valid. Di sisi lain uji reliabilitas nampaknya juga menunjukkan hasil yang juga sama, di mana uji reliabilitas itu sendiri berfungsi untuk mengetahui apakah alat ukur yang digunakan konsisten mengukur dari waktu ke waktu. Pada tabel 3.0 dapat dilihat sebagai berikut :

Tabel 3. Hasil Uji Reliabilitas Instrumen

\begin{tabular}{ll}
\hline \multicolumn{2}{l}{ Frequentist Scale Reliability Statistics } \\
\hline \multicolumn{1}{l}{ Estimate } & \multicolumn{1}{c}{ Cronbach's $\boldsymbol{\alpha}$} \\
\hline Point estimate & 0.916 \\
\hline $95 \%$ CI lower bound & 0.874 \\
\hline 95\% CI upper bound & 0.946 \\
\hline $\begin{array}{l}\text { Note. The following item correlated negatively with } \\
\text { the scale: X3. }\end{array}$ \\
\hline \multicolumn{2}{l}{ Sumber: Diolah peneliti, 2021 }
\end{tabular}

Berdasarkan pada tabel 3 menunjukkan bahwa nilai Cronbach alfa sebesar 0,916. Arifin [23] menyatakan bahwa instrumen dapat dikatakan reliabel apabila nilai koefisien reliabilitas berada lebih besar atau di atas 0,5. Sedangkan 0,916>0,5 dengan begitu maka dapat dikatakan bahwa alat ukur telah sangat reliabel.

Selanjutnya setelah alat ukur dinyatakan telah valid dan juga reliabel, maka data dapat memasuki tahapan kedua yaitu Uji Asumsi Klasik. Uji pertama yang tergolong dalam uji ini ialah Uji Normalitas yang bertujuan untuk mengetahui apakah data berdistribusi normal atau tidak, uji ini merupakan syarat seluruh uji analisis di dalam statistik. Adapun dalam analisa JASP data yang diperoleh telah berdistribusi normal.

Tabel 4. Hasil Uji Homogenitas

\begin{tabular}{llll}
\hline \multicolumn{4}{l}{ Test of Homogeneity of Variances } \\
\hline Hasil Y dan X \\
\hline Levene Statistic & df $\mathbf{1}$ & df $\mathbf{2}$ & Sig. \\
\hline 9.111 & 1 & 88 & .003 \\
\hline Sumber: Diolah peneliti, 2021 & &
\end{tabular}

Kemudian uji berikutnya, Uji Homogenitas untuk mengetahui apakah data telah homogen atau tidak, Implikasi dari data yang tidak homogen adalah data dinilai tidak bisa mencerminkan keseteraan atau terlalu banyak varians [5]. Pada tabel 4.0 dapat dilihat bahwa nilai sig. sebesar $0.003<0,05$ maka data dinyatakan homogen.

Karena data yang diperoleh telah berdistribusi normal dan memiliki sedikit varians di dalamnya maka data dapat dialnjutkan ke tahapan inti, yaitu analisa korelasi menggunakan Uji Korelasi Product Moment Pearson. Uji korelasi ini ditujukan untuk bisa melihat hubungan antara variabel X terhadap variabel Y. Pada 
tabel 5 telah disertakan hasil uji korelasi pearson di mana nilai $p=0,001<0,05$. Dengan demikian terdapat korelasi signifikan di antara perceived organizational support dengan organizational commitment anggota UKKI selama berlangsungnya pandemi Covid 19 .

Tabel 5. Hasil Uji Korelasi Product Moment Pearson

\begin{tabular}{|c|c|c|c|c|c|c|c|}
\hline \multicolumn{8}{|c|}{ Factor Covariances } \\
\hline \multicolumn{8}{|c|}{$95 \%$ Confidence Interval } \\
\hline & $\begin{array}{c}\text { Esti } \\
\text { mat } \\
\text { e }\end{array}$ & $\begin{array}{l}\text { Std } \\
\text { Err } \\
\text { or }\end{array}$ & $\begin{array}{c}\text { Z- } \\
\text { valu } \\
\text { e }\end{array}$ & $\mathrm{p}$ & $\begin{array}{l}\text { Lo } \\
\text { wer }\end{array}$ & $\begin{array}{l}\text { Up } \\
\text { per }\end{array}$ & $\begin{array}{l}\text { Std. } \\
\text { Est. } \\
\text { (all } \\
\text { ) }\end{array}$ \\
\hline $\begin{array}{l}\text { Perceived } \\
\text { Organizati } \\
\text { onal }\end{array}$ & 0.93 & 0.0 & 25.5 & $<$ & 0.8 & 1.0 & 0.9 \\
\hline $\begin{array}{l}\text { Support } \\
\rightarrow \\
\text { Komitmen } \\
\text { Organisasi }\end{array}$ & 6 & 37 & 96 & .001 & 64 & 08 & 36 \\
\hline
\end{tabular}

Berdasarkan pada hasil analisa di atas maka bisa diinterpretasikan bahwa terdapat hubungan di antara perceived organizional support dengan organizational commitment. Dengan demikian maka hasil penelitian ini didukung oleh penelitian sebelumnya yang menguji dua variabel yang sama sekaligus membuktikan bahwa hipotesa telah diterima. Beberapa penelitian terdahulu tersebut di antaranya ialah penelitian yang dilakukan oleh Mangundjaya [19] atau penelitian oleh Mujiasih [16], di mana mereka sepakat membuktikan bahwa persepsi dukungan organisasi telah memiliki impact terhadap komitmen organisasi. Oleh karena itu, maka rendahnya komitmen pada para anggota UKKI salah satunya disebabkan oleh peran dukungan organisasi yang di rasa kurang bagi para anggotanya. Dengan kata lain,. menurunnya komitmen organisasi diikuti secara linear dengan rendahnya kesejahteraan yang diberikan oleh organisasi UKKI kepada anggota di dalamnya

Seperti yang telah disinggung di atas, perceived organizional support dapat mencakup dua aspek, yaitu penghargaan terhadap berbagai kontribusi anggota melalui reward yang harus diberikan, serta peduli terhadap kesejahteraan anggota dengan cara melalui mendengarkan aspirasi oleh mereka secara seksama, dan lain sebagainya. Dari dua penjelasan tersebut sebenarnya telah dapat kita ketahui bahwa untuk menumbuhkan semangat komitmen organisasi pada anggota UKKI, organisasi tersebut harusnya mampu memberikan kepastian terhadap aspek kesejahteraan anggotanya dengan menyediakan kepemimpinan yang bersifat demokratis, serta mengupayakan berbagai bentuk penghargaan atas segala nilai daya juang atau kontribusi yang diberikan kepada organisasi, terlebih dalam situasi pandemi ini. Sebagai contoh ialah UKKI perlu menghargai setiap peserta yang telah bersedia memasuki Zoom terlebih mengikuti kegiatan dengan mengakui dan menghargai para peserta yang datang (dukungan sosial) serta sebisa mungkin memberikan dukungan seperti halnya menyediakan anggaran khusus kuota internet bagi para anggota yang dirasakan sangat membutuhkan kerja sama tersebut.

Jika kita ulas kembali masa pandemi telah sangat berdampak terhadap segala aspek di dalam kehidupan di masyarakat, termasuk efek bagi keberlangsungan organisasi UKKI Universitas Negeri Surabaya. Selama pandemi, kegiatanpun menjadi serba terbatas atau bahkan terpaksa harus ditiadakan. Hal ini merupakan indikasi bahwa para anggota UKKI membutuhkan lebih banyak dukungan dalam melakukan kegiatan di organisasi, karena masa pandemi saat ini menyebabkan para anggota menjadi kurang bersemangat berkegiatan terlebih dilakukan secara daring. Dengan diberikannya dukungan terhadap anggota UKKI tersebut diharapkan mampu menumbuhkan semangat para anggota dalam berkegiatan di organisasi meskipun masa pandemi ini. Melalui cara adanya dukungan tersebut, diharapkan organisasi ini dapat berjalan dengan baik supaya dapat tercapai organizational commitment positif di dalam organisasi kemahasiswaan UKKI. Adapun bentuk dari proses pemberian dukungan tersebut adalah dengan cara menyediakan reward baik secara moral ataupun formal seperti dukungan sosial, adanya pengakuan, menghargai pertemanan di antara anggota organisasi serta menyediakan bantuan materiil untuk anggota yang dinilai membutuhkan bantuan kuota internet guna memperlancar hubungan daring itu sendiri. Meskipun demikian fokus mekanisme pemberian tersebut perlu dijelaskan secara lebih detail lagi, misal mengkaji hubungan antara birokrasi Unesa dengan peranannya atau tanggung jawab terkait menghidupkan organisasi kemahasiswaan di region tersebut.

\section{A. KESIMPULAN}

\section{KESIMPULAN DAN SARAN}

Pandemi Covid-19 yang telah melanda memiliki dampak terhadap semua masyarakat, tidak terkecuali organisasi kemahasiswaan UKKI Universitas Negeri Surabaya. Adanya pandemi Covid 19 ini berdampak pada rencana kegiatan yang telah dirancangkan oleh UKKI pun berubah bahkan adayang harus dihentikan untuk mengurangi resiko penyebaran Covid 19 dan dialihkan secara daring melalui web. Dari data yang telah didapat dan diuji membuktikan bahwa terdapat 
hubungan antara perceived organizational support (POS) dengan variabel organizational commitment. Oleh sebab itu UKKI diharapkan dapat meningkatkan peran organisasi dalam mendukung adanya hambatanhambatan, misal komunikasi selama pandemi tersebut atau dengan kata lain UKKI perlu unruk meningkatkan nilai dari perceived organizational support sebab hal tersebut berdampak terhadap peningkatan komitmen anggota UKKI selama pandemi.

\section{B. SARAN}

Diharapan organisasi UKKI Universitas Negeri Surabaya mempertimbangkan peran upaya pemberian dukungan kepada anggota UKKI untuk meningkatkan kesejahteraan angotanya dalam rangka berorganisasi. Dukungan yang diberikan dapat berwujud dukungan moral maupun material. Sehingga dengan begitu dapat meningkatkan komitmen organisasi yang berdampak baik terhadap setiap kegiatan yang dilakukan di dalam organisasi UKKI dengan terciptanya nilai komitmen organisasi yang tinggi pada anggota itu sendiri. Pada penelitian lebih lanjut, diharapkan mampu meneliti hubungan lain yang relevan di luar pengaruh perceived organizational support terhadap kajian organizational commitment sehingga mampu menjelaskan variabel lain yang juga berkontribusi mengakibatkan fenomena rendahnya komitmen pada anggota UKKI atau dapat menambahkan variabel lain secara simultan.

\section{REFERENSI}

[1] Satgas Penanganan COVID, "Peraturan Pemerintah Republik Indonesia Nomor 21 Tahun 2020 tentang PSBB - Regulasi | Satgas Penanganan COVID-19," covid19.go.id, 2020.

[2] A. I, "COVID 19: threat and fear in Indonesia," Psychol. Trauma Theory, Res. Pract. Policy, vol. 12, no. 5, pp. 488-490, 2020.

[3] K. Nurul Fahmi Sultan, Rica Yulianti, "Pengaruh Gaya Kepemimpinan dan Komitmen Organisasi Terhadap Kinerja Karyawan Saat Pandemi Covid 19," http://jurnal.poliupg.ac.id/index.php/akunsika, 2021.

[4] H. S. Athar, "The Influence of Organizational Culture on Organizational Commitment Post Pandemic COVID-19," Int. J. Multicult. Multireligious Underst., 2020.

[5] M. Petriova, V. Koval, M. Tepavicharova, A. Zerkal, A. Radchenko, and N. Bondarchuk, "The interaction between the human resources motivation and the commitment to the organization," J. Secur. Sustain. Issues, vol. 9, no. 3, pp. 919-929, 2020, doi: 10.9770/jssi.2020.9.3(17).

[6] J. Meyer and N. Allen, Commitment in the workplace: theory, research, and application. 2012.

[7] R. M. Steers, "Antecedents and outcomes of organizational commitment.," Adm. Sci. Q., 1977, doi: 10.2307/2391745.

[8] Hrebinak and Alutto, "Personal and rolerelated factors in the development of organizational commitment," Adm. Sci. Q., vol. 17, no. 4, pp. 555-573, 1972, doi: https://doi.org/10.2307/2393833.

[9] Y. Wiener, "Commitment in organizations: a normative view," Acad. Manag. Rev., vol. 7, no. 3, pp. 418-428, 1982, doi: https://doi.org/10.2307/257334.

[10] O'Reilly and Chatman, “Organizational commitment and psychological attachment: The effects of compliance, identification, and internalization on prosocial behavior," J. Appl. Psychol., vol. 71, no. 3, pp. 492-499, 1986, doi: https://doi.org/10.1037/0021-9010.71.3.492.

[11] N. Teresia and T. Suyasa, "Komitmen organisasi dan organizational citizenship behavior pada karyawan call centre di PT X," J. Phonesis, vol. 10, no. 2, pp. 154-169, 2008.

[12] A. Nurul and S. Rohmat, "Pengaruh budaya organisasi terhadap komitmen organisasi karyawan PT. Telekomunikasi Indonesia (Persero) Tbk Kantor Witel Bandung," Int. J. Mach. Tools Manuf., vol. 5, no. 1, pp. 985-992, 2018.

[13] K. Matzler, B. Renzl, T. Mooradian, G. von Krogh, and J. Mueller, "Personality traits, affective commitment, documentation of knowledge, and knowledge sharing," Int. J. Hum. Resour. Manag., vol. 22, no. 2, pp. 296310, 2011, doi: https://doi.org/10.1080/09585192.2011.54015 6.

[14] C. Lee, G. H. Huang, and S. J. Ashford, "Job insecurity and the changing workplace: recent developments and the future trends in job insecurity research," Annu. Rev. Organ. Psychol. Organ. Behav., vol. 5, no. 1, pp. 335359, 2018.

[15] Sianipar and Haryanti, "Hubungan komitmen organisasi dan kepuasan kerja dengan intensi turnover pada karyawan bidang produksi $\mathrm{CV}$ X," Psikodimensia, vol. 13, no. 1, pp. 98-114, 2014 , doi: https://doi.org/10.24167/psiko.v13i1.281. 
[16] Mujiasih, "Hubungan antara persepsi dukungan organisasi (perceived organizational support) dengan keterikatan karyawan," J. Psikol., vol. 14, no. 1, pp. 40-51, 2015, doi: https://doi.org/10.14710/jpu.14.1.40-51.

[17] Rhoades and Eisenberger, "Perceived organizational support: a review of the literature," J. Appl. Psychol., vol. 87, no. 4, pp. 698-714, 2002, doi: https://doi.org/10.1037/0021-9010.87.4.698.

[18] S. Robbins and T. Judge, Perilaku Organisasi. Jakarta: Salemba Humanika, 2008.

[19] M. Wustari, "Persepsi dukungan organisasi versus kepuasan kerja dan perannya terhadap perilaku kewarganegaraan organisasi," $J$. Psikol., vol. 11, no. 2, p. 9, 2012.

[20] M. Jannah, Metodologi penelitian kuantitatif untuk psikologi. Unesa University Press, 2018.

[21] Sugiyono, Statistika untuk penelitian. Alfabeta, 2017.

[22] Gunawan, Pengantar statistika inferensial. Malang: PT Rajagrafindo Persada, 2015.

[23] Z. Arifin, "Kriteria instrumen dalam suatu penelitian," J. THEOREMS (The Orig. Res. Math., vol. 2, no. 1, pp. 28-36, 2017. 